\title{
The paradoxical future of digital learning
}

\author{
Mark Warschauer
}

Published online: 26 September 2007

(C) Springer Science+Business Media, LLC 2007

\section{Erratum to: Learn Inq (2007) 1:41-49 \\ DOI 10.1007/s11519-007-0001-5}

The following citations were omitted from the published article on page 44:

My own research (e.g., Warschauer, Knobel, \& Stone, 2004) similarly has documented how reading and writing ability and basic cultural literacy strongly mediate students' ability to make use of the Internet to find and use information or create meaningful multimodal content, whether in school or in out-of-school settings. Indeed, the divides allegedly attributed to unequal information literacy or multimedia literacy most frequently have their roots in differential access to basic reading and writing competency and cultural capital (see, e.g., Warschauer, 2003b; Warschauer, Knobel, \& Stone, 2004).

My own research in culturally and linguistically diverse laptop schools provides additional examples of how technology use can help students achieve both new and traditional literacies (Warschauer, 2006; Warschauer, Grant, Del Real, \& Rousseau, 2004).

The online version of the original article can be found under doi: 10.1007/s11519-007-0001-5.

M. Warschauer $(\bowtie)$

University of California, 2001 Berkeley Place, Irvine, CA 92697-5500, USA

e-mail: markw@uci.edu 